Open Access

\title{
Performance of noninvasive ventilation in acute respiratory failure in critically ill patients: a prospective, observational, cohort study
}

Thiago Domingos Corrêa ${ }^{1 *}$, Paula Rodrigues Sanches ${ }^{1}$, Lúbia Caus de Morais ${ }^{1}$, Farah Christina Scarin ${ }^{1}$, Eliézer Silva ${ }^{1}$ and Carmen Sílvia Valente Barbas ${ }^{1,2}$

\begin{abstract}
Background: Noninvasive ventilation (NIV) is used in critically ill patients with acute respiratory failure (ARF) to avoid endotracheal intubation. However, the impact of NIV use on ARF patient's outcomes is still unclear. Our objectives were to evaluate the rate of NIV failure in hypoxemic patients with an arterial carbon dioxide partial pressure $\left(\mathrm{PaCO}_{2}\right)<45 \mathrm{mmHg}$ or $\geq 45 \mathrm{mmHg}$ at ICU admission, the predictors of NIV failure, ICU and hospital length of stay and 28-day mortality.
\end{abstract}

Methods: Prospective single center cohort study. All consecutive patients admitted to a mixed ICU during a three-month period who received NIV, except for palliative care purposes, were included in this study. Demographic data, APACHE II score, cause of ARF, number of patients that received NIV, incidence of NIV failure, length of ICU, hospital stay and mortality rate were compared between NIV failure and success groups.

Results: Eighty-five from 462 patients (18.4\%) received NIV and 26/85 (30.6\%) required invasive mechanical ventilation. NIV failure patients were comparatively younger (67 \pm 21 vs. $77 \pm 14$ years; $p=0.031$ ), had lower arterial bicarbonate $(p=0.005)$, lower $\mathrm{PaCO}_{2}$ levels $(p=0.032)$, higher arterial lactate levels $(p=0.046)$ and APACHE II score ( $p=0.034$ ) compared to NIV success patients. NIV failure occurred in $25.0 \%$ of patients with $\mathrm{PaCO}_{2} \geq 45 \mathrm{mmHg}$ and in $33.3 \%$ of patients with $\mathrm{PaCO}_{2}<45 \mathrm{mmHg}(p=0.435)$. NIV failure was associated with an increased risk of in-hospital death (OR 4.64, $95 \%$ Cl 1.52 to $14.18 ; p=0.007$ ) and length [median (IQR)] of ICU [12 days (8-31) vs. 2 days (1-4); $p<0.001$ ] and hospital [30 (19-42) vs. 15 (9-33) days; $p=0.010$ ] stay. Predictors of NIV failure included age (OR 0.96, $95 \% \mathrm{Cl} 0.93$ to 0.99; $p=0.007)$ and APACHE II score (OR 1.13, $95 \% \mathrm{Cl} 1.02$ to 1.25; $p=0.018)$.

Conclusion: NIV failure was associated with an increased risk of in-hospital death, ICU and hospital stay and was not affected by baseline $\mathrm{PaCO}_{2}$ levels. Patients that failed were comparatively younger and had higher APACHE II score, suggesting the need for a careful selection of patients that might benefit from NIV. A well-designed study on the impact of a short monitored NIV trial on outcomes is needed.

Keywords: Respiratory insufficiency, Noninvasive ventilation, Hypoxemia, Intensive care unit, Mortality, Outcomes

\footnotetext{
* Correspondence: thiago.correa@einstein.br

${ }^{1}$ Intensive Care Unit, Hospital Israelita Albert Einstein, Av. Albert Einstein, 627/

701, $5^{\circ}$ andar, São Paulo CEP: 05651-901, Brazil

Full list of author information is available at the end of the article
} 


\section{Background}

Noninvasive ventilation (NIV) has been established as a useful and safe method to improve gas exchange for critically ill patients with different etiologies of acute respiratory failure (ARF) [1, 2]. NIV decreases work of breathing, improves arterial oxygenation and alveolar ventilation, prevents the use of invasive mechanical ventilation, reduces the incidence of ventilator associated pneumonia, decreases the length of intensive care unit (ICU) stay and mortality mainly due to chronic obstructive pulmonary disease exacerbations $[3,4]$ and acute cardiogenic pulmonary edema [5-8].

Nevertheless, the use of NIV to support other etiologies of ARF remains controversial [9-11]. The multifactorial etiology and the heterogeneity of patients classified as ARF patients may justify different results obtained with NIV application [12]. The available evidence suggests caution in the use of NIV in patients with acute hypoxemic respiratory failure especially in acute respiratory distress syndrome (ARDS) and community-acquired pneumonia due to high NIV failure rates [11, 13, 14].

The overall incidence of NIV failure defined by the need of intubation and invasive mechanical ventilation reported in the literature can vary widely, approaching $50 \%$ in patients with community-acquired pneumonia and ARDS $[11,15]$. The reasons for NIV failure are most commonly related to the incapacity to improve oxygenation, inability to correct dyspnea, incapacity to manage copious secretions, mask discomfort, agitation, anxiety, hemodynamic instability and progression of ARF [15]. Delayed identification of patients who fail on NIV may result in late intubation and initiation of invasive mechanical ventilation, which have been associated with increased morbidity and mortality [11].

Therefore, it is imperative to identify the variables that can help predict patients who will fail on NIV as early as possible, and thus allow a prompt intubation in cases it will be necessary [11].

Our objective was to evaluate the rate of NIV failure in hypoxemic patients with an arterial carbon dioxide partial pressure $\left(\mathrm{PaCO}_{2}\right)$ lower than $45 \mathrm{mmHg}$ or equal to or higher than $45 \mathrm{mmHg}$ at ICU admission. We also aimed to evaluate the predictors of NIV failure, intensive care and hospital length of stay, mortality rate at day 28 and the main complications associated with NIV.

\section{Methods}

\section{Study design and patient selection}

This prospective observational single center cohort study was conducted in a forty-one bed, open mixed ICU of a tertiary care hospital in São Paulo, Brazil. This study was approved by the institutional review board of Hospital Albert Einstein, who waived the need for informed consent in view of the observational characteristic of the study (protocol number: 19301213.5.0000.0071).

During a three-month period, all consecutive patients admitted to the ICU that presented a peripheral oxygen saturation $\left(\mathrm{SpO}_{2}\right)$ lower than $90 \%$ despite oxygen delivered through a Venturi Mask [fraction of inspired oxygen $\left(\mathrm{FiO}_{2}\right)$ around of $50 \%$ ] or by an oxygen bag $\left(\mathrm{FiO}_{2}\right.$ around $100 \%$ ) that received NIV, except for palliative care purposes, were included in this study [16].

Patients were excluded when they were under eighteen, had previous tracheostomy, used NIV for palliative care or presented contraindications to receiving NIV, including cardiac or respiratory arrest, Glasgow Coma Scale $\leq 10$, severe upper gastrointestinal bleeding, hemodynamic instability, unstable cardiac arrhythmia, facial surgery or trauma, upper airway obstruction, inability to cooperate or protect the airway, inability to clear respiratory secretions or high risk for aspiration. The researches followed the patients and did not interfere in the ICU medical and multidisciplinary staff decisions.

\section{Protocol of niv use in the ICU}

Noninvasive ventilation was applied to patients admitted to the ICU that presented a $\mathrm{SpO}_{2}$ lower than $90 \%$ despite oxygen delivered through a Venturi Mask $\left(\mathrm{FiO}_{2}\right.$ around of $50 \%)$ or by an oxygen bag $\left(\mathrm{FiO}_{2}\right.$ around 100 \%) [16]. Noninvasive ventilation was delivered by a total face mask, secured with head straps, coupled to a BIPAP Vision $^{\mathrm{Tm}}$ (Respironics INC ${ }^{\oplus}$, Pennsylvania, USA). For patients with a nasogastric tube, a seal connector in the dome of the mask was used to minimize air leakage. After the mask was attached to the patient, pressure support could be increased from 5 up to $20 \mathrm{~cm} \mathrm{H}_{2} \mathrm{O}$ to obtain an exhaled tidal volume of $6 \mathrm{~mL} / \mathrm{kg}$ of predicted body weight, a respiratory rate lower than 30 breaths per minute, attenuation of respiratory accessory muscle activity and achievement of patient's comfort. Positive endexpiratory pressure (PEEP) was initiated at $5 \mathrm{~cm} \mathrm{H}_{2} \mathrm{O}$ and increased in steps of 2 to $3 \mathrm{~cm} \mathrm{H}_{2} \mathrm{O}$ up to $15 \mathrm{~cm}$ $\mathrm{H}_{2} \mathrm{O}$ until the $\mathrm{FiO}_{2}$ requirement was $60 \%$ or less in patients with hypoxemic respiratory failure.

All ventilator settings could be re-adjusted by the attending physician and by a chest physiotherapist, based on the results of continuous oximetry, measurements of arterial blood gases (specially $\mathrm{PaCO}_{2}$ and $\mathrm{pH}$ ) and ventilator parameters (expiratory tidal volume, respiratory rate, and mask leakage) as well as on patients' comfort. A baseline arterial blood gas analysis was performed after patient's stabilization on NIV.

Patients did not usually receive sedatives. If they were agitated and uncomfortable with the mask, intravenous morphine or dexmedetomidine was initiated [17]. All patients were monitored with continuous electrocardiography and $\mathrm{SpO}_{2}$. The heads of the beds were kept 
elevated at $30^{\circ}$. Each patient was evaluated periodically according to the institutional protocol by the attending physician and by a respiratory physiotherapist in order to access the possibility to reduce or increase PEEP or NIV discontinuation/continuation.

NIV success patients were maintained coupled to a BIPAP vision continuously during a 24 -h period. Afterwards, NIV parameters were re-adjusted based on $\mathrm{SpO}_{2}$, arterial blood gas analysis (specially $\mathrm{PaCO}_{2}$ levels), ventilator parameters (expiratory tidal volume, respiratory rate and mask leakage) and patient's comfort. When $\mathrm{FiO}_{2}$ was lower than $50 \%$, respiratory rate lower than 30 breaths per minute, expiratory tidal volume higher than $5 \mathrm{~mL} / \mathrm{kg}$ of predicted body weight with a pressure support lower than $10 \mathrm{~cm} \mathrm{H}_{2} \mathrm{O}$ and PEEP lower than $8 \mathrm{~cm}$ $\mathrm{H}_{2} \mathrm{O}$, NIV was discontinued and oxygen ventury mask of $50 \%$ initiated. If an oxygen ventury mask of $50 \%$ was well tolerated during a one-hour period, the ventury mask of $50 \%$ was alternated with NIV ( $1 \mathrm{~h}$ in ventury mask of $50 \%$ and $3 \mathrm{~h}$ in NIV) until the patient could stay spontaneously breathing. The maximal time allowed on full NIV support was $24 \mathrm{~h}$. After $24 \mathrm{~h}$ on NIV, patients that could not stay for at least one hour on oxygen ventury mask was defined dependent on NIV and was intubated and mechanically ventilated.

\section{Endotracheal intubation}

Detection of NIV failure, the decision to intubate patients and start mechanical ventilation were made by the attending physician. Patients who failed treatment with NIV underwent endotracheal intubation with cuffed endotracheal tubes (internal diameter of 7.5 to $8.5 \mathrm{~mm}$ ) and were mechanically ventilated (Servo-i; Maquet Critical Care, Solna, Sweden).

Criteria for endotracheal intubation included failure to maintain an arterial oxygen partial pressure $\left(\mathrm{PaO}_{2}\right)>60$ mmHg or $\mathrm{SpO}_{2}>90 \%$ with an $\mathrm{FiO}_{2}$ equal to or greater than $60 \%, \mathrm{PaCO}_{2}$ higher than $60 \mathrm{mmHg}$ with $\mathrm{pH}$ lower than 7.25 , inability to protect the airways or to manage copious tracheal secretions, hemodynamic or electrocardiographic instability, inability to tolerate the face mask, inability to correct dyspnea and progression of respiratory failure [16].

\section{Outcome measures}

Demographic data, etiology of respiratory failure, APACHE II score [18], vital signs, electrolytes, hemoglobin, platelets, white blood cell count, serum creatinine, arterial lactate, $\mathrm{FiO}_{2}$, ratio of the arterial oxygen partial pressure to the fraction of inspired oxygen $\left(\mathrm{PaO}_{2} / \mathrm{FiO}_{2}\right)$, arterial $\mathrm{pH}, \mathrm{PaCO}_{2}$, arterial lactate, number of patients that used NIV, number of patients that needed endotracheal intubation (NIV failure), in-hospital mortality rate, mortality at day 28 , length of ICU and hospital stay and complications related to NIV were recorded.

Our primary outcome was the incidence of NIV failure, defined by the need of endotracheal intubation and mechanical ventilation in hypoxemic patients with $\mathrm{PaCO}_{2}<45 \mathrm{mmHg}$ and $\geq 45 \mathrm{mmHg}$ at ICU admission. Secondary outcomes were the main indications for acute application of NIV, the predictors of NIV failure, ICU and hospital lengths of stay, in-hospital and mortality at day 28 and the main complications associated with noninvasive ventilation.

\section{Statistical analysis}

Categorical variables were displayed as absolute and relative frequencies. Numerical variables were presented as mean and standard deviation (SD) or median with interquartile ranges (IQR) in case of non-normal distribution, tested by the Kolmogorov-Smirnov test.

Comparisons were made between NIV failure and NIV success groups and between patients with $\mathrm{PaCO}_{2}<45$ $\mathrm{mmHg}$ and $\geq 45 \mathrm{mmHg}$ at ICU admission. Categorical variables were compared with chi-square test or with Fisher exact test when appropriate. Continuous variables were compared using independent $t$ test or Mann-Whitney $U$ test in case of non-normal distribution. Survival curves at day 28 were performed according to the Kaplan-Meier method and compared with a log-rank test.

A univariate logistic regression analysis was performed to identify which factors (predictors) were associated with NIV failure. Only variables presented in more than five patients in each group were included. A multivariate logistic regression analysis with backward elimination procedure including all predictors showing a $p$ value $\leq 0.25$ in the univariate analysis was undertaken to obtain an adjusted odds ratio (OR) with $95 \%$ confidence interval (CI) and define which variables were independently associated with NIV failure.

Statistical tests were 2-sided, and a $p<0.05$ was considered statistically significant. Statistical analyses were performed using $\mathrm{IBM}^{\bullet} \mathrm{SPSS}^{\circ}$ Statistics version 22.0 for Windows.

\section{Results \\ Patients}

In a three-month period, 462 patients were admitted to the ICU. Ninety-one patients fulfilled the criteria for NIV use, but six patients were excluded because they used NIV for palliative care purposes. Therefore, eightyfive patients were included in the study (Fig. 1).

The baseline characteristics, clinical, physiological and laboratorial parameters of studied patients are presented on Table 1. NIV failure patients were comparatively younger, had lower arterial bicarbonate, and lower $\mathrm{PaCO}_{2}$ levels and had higher arterial lactate levels and 


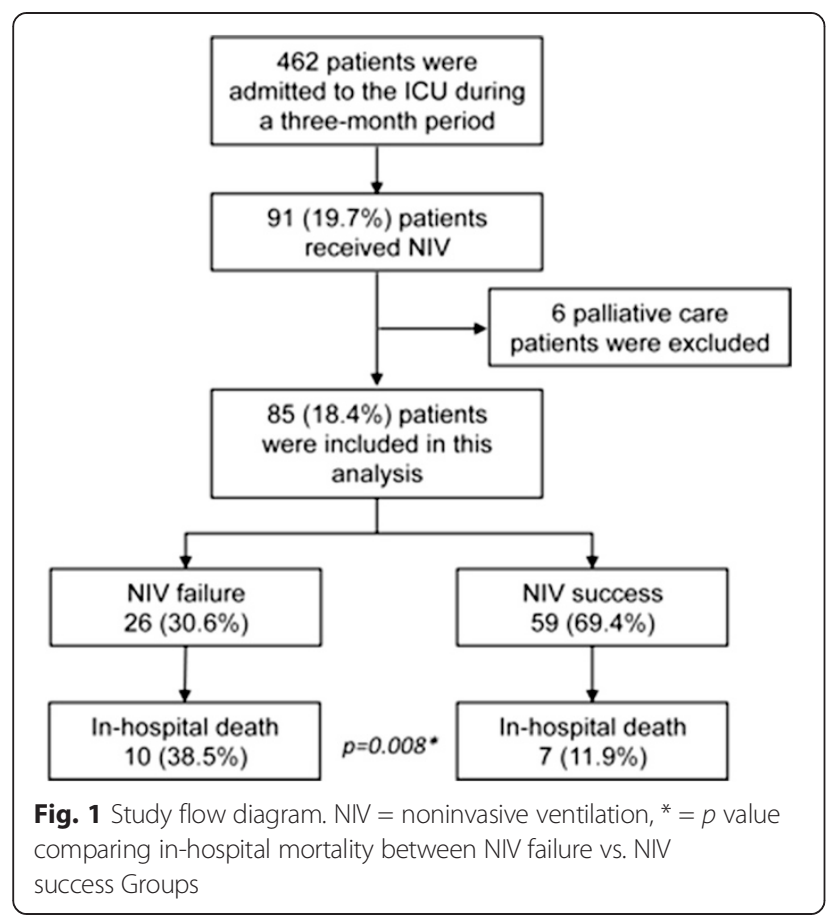

APACHE II score compared to NIV success patients (Table 1). The main etiologies of acute respiratory failure did not differ between the two groups (Table 2). Concerning comorbidities, NIV failure group had a higher number of transplanted patients in comparison to NIV success group (Table 1).

\section{Response to NIV and complications}

NIV success occurred in 69.4\% (59/85) of patients (NIV Success Group) and NIV failure occurred in $30.6 \%(26 / 85)$ of patients that needed intubation and mechanical ventilation (NIV failure Group) (Table 1 and Fig. 1). NIV failure occurred in $25.0 \%(7 / 28)$ of patients with $\mathrm{PaCO}_{2} \geq 45$ mmHg and in $33.3 \%$ (19/57) of patients with $\mathrm{PaCO}_{2}<45$ $\mathrm{mmHg}$ (OR $0.67,95 \%$ CI 0.24 to $1.84 ; p=0.435)$ (Table 1$)$.

In $61.5 \%(16 / 26)$ of patients, NIV failure occurred during the first $24 \mathrm{~h}$ of noninvasive mechanical ventilation. The main reasons for endotracheal intubation included progression of hypoxemia in $65.4 \%$ (17/26), neurological deterioration in $19.2 \%(5 / 26)$, gastric distension $7.7 \%(2 /$ 26), hemodynamic instability $3.8 \%(1 / 26)$ and patients' dangerous agitation $3.8 \%(1 / 26)$ (Table 2$)$.

The only complication associated with NIV was gastric distension reported in 3/26 (11.5\%) NIV failure patients vs. $4 / 59$ (6.8 \%) in NIV success groups $(p=0.670$; Table 3).

\section{Length of ICU and hospital stay}

The median lengths of ICU and hospital stays were significantly higher in NIV failure in comparison to the NIV success groups (Table 3 ). The median (IQR) length of ICU stay [2 (1-8) vs. $4(2-10)$, respectively for $\mathrm{PaCO}_{2} \geq$ $45 \mathrm{mmHg}$ and $<45 \mathrm{mmHg} ; p=0.101]$ and hospital stay [19 (9-30) vs. 21 (12-37), respectively for $\mathrm{PaCO}_{2} \geq 45$ $\mathrm{mmHg}$ and $<45 \mathrm{mmHg} ; p=0.165$ ] were not affected by baseline $\mathrm{PaCO}_{2}$ levels.

\section{Mortality}

In-hospital mortality rate was higher in the NIV failure patients compared to the NIV success patients [10/26 (38.5\%) vs. 7/59 (11.9\%), respectively for NIV failure and NIV success groups; $p=0.008$ ] (Table 3). NIV failure was associated with an increased risk of in-hospital death (OR $4.64,95 \%$ CI 1.52 to $14.18 ; p=0.007)$ while mortality at day 28 [5/26 (19.2\%) vs. 4/59 (6.8\%), respectively for NIV failure and NIV success groups; $p=0.124$ ] did not differ between NIV failure and success groups (Table 3 and Figure 2).

In-hospital mortality [3/28 patients $(10.7 \%)$ vs. $14 / 57$ patients $(24.6 \%)$, respectively for $\mathrm{PaCO}_{2} \geq 45 \mathrm{mmHg}$ and $<45 \mathrm{mmHg} ; p=0.160]$ and 28 -day mortality [3/28 patients $(10.7 \%)$ vs. $6 / 57$ patients $(10.5 \%)$, respectively for $\mathrm{PaCO}_{2} \geq 45 \mathrm{mmHg}$ and $<45 \mathrm{mmHg}, p=1.000$ ] did not differ between patients with baseline $\mathrm{PaCO}_{2} \geq 45$ $\mathrm{mmHg}$ or $<45 \mathrm{mmHg}$.

\section{Predictors of NIV failure}

From the initial model containing 10 predictors, the backward elimination procedure yielded a reduced model containing age (OR 0.96, $95 \%$ CI 0.93 to $0.99 ; p=0.007$ ) and APACHE II score (OR 1.13, $95 \%$ CI 1.02 to $1.25 ; p=0.018$ ) (Table 4). Interaction between age and APACHE II score was not significant $(p=0.11)$.

\section{Discussion}

This study showed a success rate of approximately $70 \%$ of noninvasive ventilation in a general ICU population with acute hypoxemic respiratory failure. The initial $\mathrm{PaCO}_{2}$ levels $(<45 \mathrm{mmHg}$ or $\geq 45 \mathrm{mmHg}$ ) was not related to NIV failure/success. Patients who failed on NIV and received invasive mechanical ventilation were sicker, comparatively younger, had higher ICU and hospital length of stay and had higher in-hospital mortality rate. The multivariate logistic regression analysis showed that APACHE II score was an independent predictor of NIV failure, suggesting that sicker patients should be carefully monitored during the NIV trial regarding heart rate, mean arterial blood pressure and arterial lactate levels besides monitoring $\mathrm{SpO}_{2}, \mathrm{PaO}_{2}$, $\mathrm{PaCO}_{2}, \mathrm{pH}$, respiratory rate and tidal volume for early prediction of NIV failure.

The main evidence-based clinical indications for NIV use in the critical care setting are exacerbations of chronic obstructive pulmonary disease [3,4] and acute cardiogenic pulmonary edema [5-8]. Nevertheless, 
Table 1 Baseline characteristics of study patients

\begin{tabular}{|c|c|c|c|}
\hline Characteristics & $\begin{array}{l}\text { NIV failure } \\
26(30.6 \%) \\
\end{array}$ & $\begin{array}{l}\text { NIV success } \\
59(69.4 \%)\end{array}$ & $P$ value ${ }^{\pi}$ \\
\hline Age (years) & $67(21)$ & $77(14)$ & $0.031^{a}$ \\
\hline Male gender, $n^{\circ}(\%)$ & $17(65.4)$ & $27(45.8)$ & $0.106^{\mathrm{b}}$ \\
\hline Mean arterial pressure $(\mathrm{mmHg})$ & $81(24)$ & $93(21)$ & $0.032^{a}$ \\
\hline Heart rate (beats/min) & $107(25)$ & $95(19)$ & $0.031^{\mathrm{a}}$ \\
\hline APACHE \| score & $16.0(4.7)$ & $13.4(5.3)$ & $0.034^{\mathrm{a}}$ \\
\hline Arterial pH & $7.36(0.08)$ & $7.39(0.07)$ & $0.106^{\mathrm{a}}$ \\
\hline Bicarbonate $(\mathrm{mmol} / \mathrm{L})$ & $19.6(7.3)$ & $23.7(4.7)$ & $0.005^{\mathrm{a}}$ \\
\hline $\mathrm{PaCO}_{2}(\mathrm{mmHg})$, median [IQR] & $30.8[26.6-40.1]$ & $35.3[31.5-43.5]$ & $0.032^{c}$ \\
\hline $\mathrm{PaCO}_{2} \geq 45 \mathrm{mmHg}, \mathrm{n}^{\circ}(\%)$ & $7(26.9)$ & $21(35.6)$ & $0.466^{\mathrm{b}}$ \\
\hline $\mathrm{PaO}_{2} / \mathrm{FiO}_{2}$ & $277(148)$ & $282(109)$ & $0.878^{a}$ \\
\hline Arterial lactate $(\mathrm{mg} / \mathrm{dl})$, median [IQR] & 17 [14-26] & $12[8-21]$ & $0.046^{c}$ \\
\hline Hemoglobin (mg/dl) & $10.6(2.1)$ & $11.0(2.1)$ & $0.499^{a}$ \\
\hline \multicolumn{4}{|l|}{ Reason for ICU admission, $n^{\circ}(\%)$} \\
\hline Medical & $20(76.9)$ & $53(89.8)$ & \multirow[t]{2}{*}{$0.174^{\mathrm{b}}$} \\
\hline Operative & $6(23.1)$ & $6(10.2)$ & \\
\hline \multicolumn{4}{|l|}{ Comorbidities, n (\%) } \\
\hline Diabetes Mellitus & $9(34.6)$ & $15(25.4)$ & $0.438^{\mathrm{b}}$ \\
\hline Transplantation & $7(26.9)$ & $2(3.4)$ & $0.003^{b}$ \\
\hline Chronic renal failure & $6(23.1)$ & $8(13.6)$ & $0.344^{b}$ \\
\hline Systemic hypertension & $6(23.1)$ & $17(28.8)$ & $0.792^{b}$ \\
\hline COPD & $6(23.1)$ & $12(20.3)$ & $0.779^{b}$ \\
\hline Liver cirrhosis & $4(15.4)$ & $1(1.7)$ & $0.029^{b}$ \\
\hline Coronary insufficiency & $4(15.4)$ & $12(20.3)$ & $0.766^{b}$ \\
\hline Congestive heart failure & $4(15.4)$ & $22(37.3)$ & $0.072^{b}$ \\
\hline Neoplasm & $3(11.5)$ & $7(11.9)$ & $1.000^{\mathrm{b}}$ \\
\hline None & $2(7.7)$ & $12(20.3)$ & $0.209^{b}$ \\
\hline
\end{tabular}

Values are mean (SD) or median [IQR] when indicated

$\boldsymbol{\uparrow}=p$ values and the respective statistical tests comparing NIV failure vs. NIV success groups. ${ }^{a}=$ Independent $t$-test, ${ }^{b}=$ Fisher's exact test, ${ }^{c}=$ Mann-Whitney $U$ test. APACHE II Acute physiology and chronic health evaluation II (The score can range from 0 to 71 , with higher scores indicating more severe illness), PaCO Partial pressure of arterial carbon dioxide, and $\mathrm{PaO}_{2} / \mathrm{FiO}_{2}$ Ratio of the arterial oxygen partial pressure to the fraction of inspired oxygen, ICU Intensive care unit, COPD Chronic obstructive pulmonary disease

Table 2 Main causes of acute respiratory failure

\begin{tabular}{|c|c|c|c|}
\hline Causes of failure, $\mathrm{n}(\%)$ & $\begin{array}{l}\text { NIV failure } \\
26(20.6 \%)\end{array}$ & $\begin{array}{l}\text { NIV success } \\
59(69.4 \%)\end{array}$ & $P$ value \\
\hline Community acquired pneumonia & $10(38.5)$ & $20(33.9)$ & 0.806 \\
\hline Cardiogenic pulmonary edema & $4(15.4)$ & $15(25.4)$ & 0.402 \\
\hline Acute respiratory distress syndrome & $5(19.2)$ & $5(8.5)$ & 0.271 \\
\hline Acute COPD & $3(11.5)$ & $7(11.9)$ & 1.000 \\
\hline Other causes of $\mathrm{ARF}^{\mathrm{a}}$ & $4(15.4)$ & $12(20.3)$ & 0.766 \\
\hline
\end{tabular}

$\uparrow=p$ values with Fisher's exact test comparing NIV failure vs. NIV success groups. COPD Chronic obstructive pulmonary disease, ${ }^{\mathrm{a}}=$ mucous plugging, atelectasis, pulmonary embolism, pulmonary contusion and neuromuscular disease advances in NIV ventilators, development of more comfortable interfaces, improvement in patients monitoring and care during NIV delivery and staff training have contributed to the dissemination of NIV application in patients with ARF of different etiologies [19-21] and increased NIV use [20].

The success rate of NIV in critically ill patients can vary widely [1-11]. The main factors associated with success or failure were the etiology of respiratory insufficiency and the presence of dysfunction of other organs besides the lungs [2]. The reported success of NIV in hypoxemic respiratory failure is around $50 \%$ while in hypercapnic respiratory failure it is around $75 \%$ [2]. In our study population, $67 \%$ (57/85) of patients had $\mathrm{PaCO} 2<45 \mathrm{mmHg}$ at baseline and the main reason for NIV start was desaturation while 
Table 3 Mortality rate, length of stay and incidence of complications associated with noninvasive positive pressure ventilation

\begin{tabular}{llll}
\hline Variables & NIV failure & NIV success & $P$ value \\
& $26(30.6 \%)$ & $59(69.4 \%)$ & \\
\hline Length of ICU stay (days) & $12[8-31]$ & $2[1-4]$ & $<0.001^{\mathrm{a}}$ \\
Length of hospital stay (days) & $30[19-42]$ & $15[9-33]$ & $0.010^{\mathrm{a}}$ \\
Mortality at day 28, n⿳0 (\%) & $5(19.2)$ & $4(6.8)$ & $0.124^{\mathrm{b}}$ \\
In-hospital mortality, no (\%) & $10(38.5)$ & $7(11.9)$ & $0.008^{\mathrm{b}}$ \\
Complications associated with NIV & & & \\
Gastric distension & $3(11.5)$ & $4(6.8)$ & $0.670^{\mathrm{b}}$ \\
\hline
\end{tabular}

१ $=p$ values for NIV failure vs. NIV success Groups. ${ }^{a}=$ Mann-Whitney $U$ test, ${ }^{\mathrm{b}}=$ Fisher's exact test and. ICU Intensive care unit. Values are median [IQR] or $n^{\circ}(\%)$ when indicated

receiving supplementary oxygen through a Venturi mask or oxygen bag. The success of NIV in this group was approximately $67 \%$ (38/57 patients), which shows that in everyday clinical practice, NIV should be attempted in the hypoxemic respiratory failure with two thirds of success without major complications when observing the use of an appropriate interface and NIV ventilator.

In our study, acute respiratory failure caused by community-acquired pneumonia was the main reason for NIV use. Intubation was avoided in $67 \%(20 / 30)$ of the patients. Our results are in accordance to a recent report on the use of NIV in severe community-acquired pneumonia with acute respiratory failure that observed NIV success in 95 out of 127 (75\%) patients, suggesting that NIV should be a good option for patients with acute respiratory failure secondary to a community-acquired pneumonia [22].

Results in the medical literature suggest that NIV use in ARDS patients must be attempted with caution, due

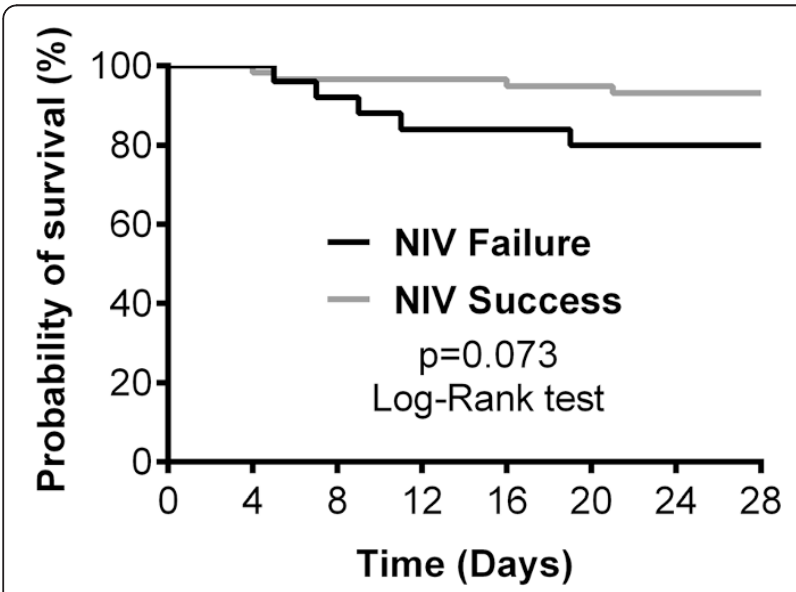

Fig. 2 Kaplan-Meier curve for 28-day survival. NIV = noninvasive ventilation to high need of intubation and mortality rates associated with failure in these patients, especially in the more severe ones [23]. Recently, the use of NIV for acute hypoxemic failure was assessed in 82 ARDS and 31 non-ARDS patients over a 3-year period in an prospective cohort study [24]. Intubation rate was significantly higher in ARDS in comparison to non-ARDS patients (61\% vs. $35 \%, p=0.015)$ and varied according to the severity of disease: $31 \%$ in mild, $62 \%$ in moderate, and $84 \%$ in severe $\operatorname{ARDS}(p=0.0016)$ [24]. NIV failure was lower among moderate ARDS patients having a $\mathrm{PaO}_{2} / \mathrm{FiO}_{2}>$ $150 \mathrm{mmHg}$ ( $45 \%$ vs. $74 \%, p=0.04$ ) [24].

Antonelli and colleagues showed in a randomized multicenter study that NIV was able to enhance oxygenation and avoid intubation in $54 \%$ of ARDS patients [25]. Avoidance of intubation resulted in reduction of ventilator-associated pneumonia, ICU length of stay and mortality [25]. In our study, only 10 of our patients had the diagnosis of ARDS with a NIV success rate of $50 \%$. The median (IQR) length of ICU stay was 3.0 (3.0-5.0) days for ARDS patients treated successfully with NIV and 18.0 (10.0-34.0) days for those who required invasive mechanical ventilation $(p=0.008)$ although the inhospital mortality did not differ between ARDS patients who failed on NIV in comparison to NIV success patients [3/5 (60 \%) vs. 0/5 (0\%), $p=0.167]$. According to these findings, instead of caution or contraindication of NIV use in ARDS patients, we suggest that a monitored ICU NIV trial should be considered in the ARDS patients due to the low mortality rates when NIV is successfully delivered [26]. However, in patients who failed the NIV trial, prompt intubation and invasive mechanical ventilation must be provided due to related high mortality rates in this population [26].

We found a higher prevalence of transplanted patients in the NIV failure group than in the NIV success group. A significant reduction in intubation rate and ICU length of stay using NIV for respiratory failure in recipients of solid organ transplantation have been reported [27-29]. Contrary to these findings, we observed a higher incidence of NIV failure in transplanted patients [7/9 (77.7 \%)]. In our study, transplanted patients were comparatively younger than non-transplanted patients (45 \pm 15 vs. $77 \pm 13$ years, respectively, $p<0.001$ ). The younger age and higher failure rate in the transplanted patients may have contributed to the finding that comparatively younger age $(67 \pm 21$ vs. $77 \pm 14)$ was an independent predictor of NIV failure in our study.

In the present study, in-hospital mortality rate was higher in the NIV failure patients compared to the NIV success patients. Recently, Schnell and colleagues analyzed 1232 patients that received NIV out of 3163 (39 \%) critically ill patients from a multicenter database [30]. First-line NIV was associated with better 60-day survival and fewer 
Table 4 Logistic regression analysis addressing the main risk factors for noninvasive positive pressure ventilation failure

\begin{tabular}{|c|c|c|c|c|c|c|}
\hline \multirow[b]{2}{*}{ Risk factors (predictors) } & \multicolumn{3}{|c|}{ Univariate analysis } & \multicolumn{3}{|c|}{ Multivariate analysis } \\
\hline & $\mathrm{OR}$ & $95 \% \mathrm{Cl}$ & $P$ value & $\mathrm{OR}$ & $95 \% \mathrm{Cl}$ & $P$ value \\
\hline Age (years) & 0.97 & $0.94-0.99$ & 0.015 & 0.96 & $0.93-0.99$ & 0.007 \\
\hline Male gender & 2.24 & $0.86-5.83$ & 0.100 & & & \\
\hline Mean arterial pressure $(\mathrm{mmHg})$ & 0.98 & $0.95-1.00$ & 0.037 & & & \\
\hline Heart rate (bpm) & 1.02 & $1.00-1.05$ & 0.037 & & & \\
\hline APACHE II score & 1.10 & $1.00-1.21$ & 0.039 & 1.13 & $1.02-1.25$ & 0.018 \\
\hline Arterial pH & 0.95 & $0.89-1.01$ & 0.116 & & & \\
\hline Bicarbonate (mmol/L) & 0.87 & $0.78-0.97$ & 0.009 & & & \\
\hline Arterial lactate (mg/dL) & 1.05 & $0.99-1.10$ & 0.081 & & & \\
\hline Transplantation & 10.50 & $2.00-54.95$ & 0.005 & & & \\
\hline Acute respiratory distress syndrome & 2.57 & $0.68-9.80$ & 0.167 & & & \\
\hline
\end{tabular}

OR Odds ratio, CI Confidence interval, APACHE II Acute physiology and chronic health evaluation II (The score can range from 0 to 71 , with higher scores indicating more severe illness)

ICU-acquired infections compared to first line intubation in patients with acute-on-chronic respiratory failure [30].

Furthermore, it has been demonstrated that critically ill patients who required endotracheal intubation and invasive mechanical ventilation following a noninvasive ventilation exhibited a higher mortality rate than patients who were directly intubated [31-33]. Conversely, due to the increased risk of death attributed to NIV failure, a short period of NIV trial in hypoxemic respiratory patients has been proposed [34]. Nevertheless, the duration of the test and what specific population of hypoxemic patients this test should be applied in, is not well established in the literature. While a short period of a NIV trial may not be enough to allow the effects of NIV to be detectable, long periods on NIV may be associated with delayed initiation of mechanical ventilation and, therefore, to worst outcomes [31]. Therefore, a welldesigned prospective controlled trial comparing a short well-monitored NIV trial to first line invasive mechanical ventilation in hypoxemic respiratory failure patients (excluding patients with absolute contra-indication or urgent need of intubation) is still needed.

Our study has limitations. This was an observational, prospective, single center study carried out in a general medical-surgical ICU for a strict period of three months and it included a small number of patients. Although our ICU has a protocol for the management of noninvasive ventilation, the identification of NIV failure and the indication for endotracheal intubation was based on the judgment of the attending physician. This variability in the day-by-day ICU medical care decisions is part of our real world and should be considered in mechanical ventilation studies. Finally, patients were ventilated with a full-face mask coupled to a BIPAP Vision ${ }^{\bullet}$ (ventilator specially designed for NIV delivery) that limits the interpretation of our results only to these settings.

\section{Conclusion}

In our prospective cohort study, NIV failure in patients with acute respiratory failure was associated with increased in-hospital mortality, ICU and hospital stay and was not affected by baseline $\mathrm{PaCO}_{2}$ levels. Patients that failed were comparatively younger and had higher APACHE II score, suggesting the need for a careful selection of patients that might benefit from NIV and the need for a close monitoring in the more severe patients during NIV.

\section{Abbreviations}

NIV: Noninvasive positive pressure ventilation; ARF: Acute respiratory failure; ICU: Intensive care unit; BIPAP: Bilevel positive airway pressure;

CPAP: Continuous positive airway pressure; APACHE II: Acute physiology and chronic health evaluation II; PEEP: Positive end-expiratory pressure;

$\mathrm{SpO}_{2}$ : Peripheral oxygen saturation; $\mathrm{PaO}_{2}$ : Arterial oxygen partial pressure; $\mathrm{PaCO}_{2}$ : Arterial carbon dioxide partial pressure; $\mathrm{FiO}_{2}$ : Fraction of inspired oxygen; $\mathrm{PaO}_{2} / \mathrm{FiO}_{2}$ : Ratio of the arterial oxygen partial pressure to the fraction of inspired oxygen; ALI: Acute lung injury; ARDS: Acute respiratory distress syndrome; COPD: Chronic obstructive pulmonary disease.

\section{Competing interests}

The authors declare have no competing interests.

\section{Authors' contributions}

TDC and CSVB devised the study protocol. TDC, PRS, LCM, FCS, CSVB participated in the enrolment of patients and in the acquisition of data. TDC, ES and CSVB analyzed the data. All authors interpreted the data, wrote, critically revised and approved the final manuscript to be published.

\section{Acknowledgments}

We thank the chest physiotherapy team of Hospital Israelita Albert Einstein for their assistance during this study and Adriana Pardini for English language review.

This study was performed at the Intensive Care Unit, Hospital Israelita Albert Einstein, São Paulo, SP, Brazil.

\section{Author details}

${ }^{1}$ Intensive Care Unit, Hospital Israelita Albert Einstein, Av. Albert Einstein, 627/ 701, $5^{\circ}$ andar, São Paulo CEP: 05651-901, Brazil. ${ }^{2}$ Pulmonary and Critical Care Division- INCOR, University of São Paulo, São Paulo, Brazil.

Received: 26 March 2015 Accepted: 2 November 2015

Published online: 11 November 2015 


\section{References}

1. Nava S, Hill N. Non-invasive ventilation in acute respiratory failure. Lancet. 2009;374:250-9.

2. Hess DR. Noninvasive ventilation for acute respiratory failure. Respir Care 2013;58:950-72.

3. Ram FS, Lightowler JV, Wedzicha JA. Non-invasive positive pressure ventilation for treatment of respiratory failure due to exacerbations of chronic obstructive pulmonary disease. Cochrane Database Syst Rev. 2003;(1):CD004104.

4. Quon BS, Gan WQ, Sin DD. Contemporary management of acute exacerbations of COPD: a systematic review and metaanalysis. Chest. 2008;133:756-66.

5. Masip J, Roque M, Sanchez B, Fernandez R, Subirana M, Exposito JA. Noninvasive ventilation in acute cardiogenic pulmonary edema: systematic review and meta-analysis. JAMA. 2005;294:3124-30.

6. Peter JV, Moran JL, Phillips-Hughes J, Graham P, Bersten AD. Effect of noninvasive positive pressure ventilation (NIPPV) on mortality in patients with acute cardiogenic pulmonary oedema: a meta-analysis. Lancet. 2006;367:1155-63.

7. Winck JC, Azevedo LF, Costa-Pereira A, Antonelli M, Wyatt JC. Efficacy and safety of non-invasive ventilation in the treatment of acute cardiogenic pulmonary edema-a systematic review and meta-analysis. Crit Care. 2006;10:R69.

8. Vital FM, Ladeira MT, Atallah AN. Non-invasive positive pressure ventilation (CPAP or bilevel NPPV) for cardiogenic pulmonary oedema. Cochrane Database Syst Rev. 2013;5, CD005351.

9. Ferrer M, Esquinas A, Leon M, Gonzalez G, Alarcon A, Torres A. Noninvasive ventilation in severe hypoxemic respiratory failure: a randomized clinical trial. Am J Respir Crit Care Med. 2003;168:1438-44.

10. Rana S, Jenad H, Gay PC, Buck CF, Hubmayr RD, Gajic O. Failure of noninvasive ventilation in patients with acute lung injury: observational cohort study. Crit Care. 2006;10:R79.

11. Antonelli M, Conti G, Moro ML, Esquinas A, Gonzalez-Diaz G, Confalonieri M, et al. Predictors of failure of noninvasive positive pressure ventilation in patients with acute hypoxemic respiratory failure: a multi-center study. Intensive Care Med. 2001;27:1718-28.

12. Keenan SP, Sinuff T, Cook DJ, Hill NS. Does noninvasive positive pressure ventilation improve outcome in acute hypoxemic respiratory failure? A systematic review. Crit Care Med. 2004;32:2516-23.

13. Agarwal R, Aggarwal AN, Gupta D, Jindal SK. Role of noninvasive positivepressure ventilation in postextubation respiratory failure: a meta-analysis. Respir Care. 2007;52:1472-9.

14. Jolliet P, Abajo B, Pasquina P, Chevrolet JC. Non-invasive pressure support ventilation in severe community-acquired pneumonia. Intensive Care Med. 2001;27:812-21.

15. Nava S, Ceriana P. Causes of failure of noninvasive mechanical ventilation. Respir Care. 2004;49:295-303.

16. Barbas CS, Isola AM, Farias AM, Cavalcanti AB, Gama AM, Duarte AC, et al. Brazilian recommendations of mechanical ventilation 2013. Part I. Rev Bras Ter Intensiva. 2014;26:89-121.

17. Demuro JP, Mongelli MN, Hanna AF. Use of dexmedetomidine to facilitate non-invasive ventilation. Int J Crit IIIn Inj Sci. 2013;3:274-5.

18. Knaus WA, Draper EA, Wagner DP, Zimmerman JE. APACHE II: a severity of disease classification system. Crit Care Med. 1985;13:818-29.

19. Girou E, Brun-Buisson C, Taille S, Lemaire F, Brochard L. Secular trends in nosocomial infections and mortality associated with noninvasive ventilation in patients with exacerbation of COPD and pulmonary edema. JAMA. 2003;290:2985-91.

20. Demoule A, Girou E, Richard JC, Taille S, Brochard L. Increased use of noninvasive ventilation in French intensive care units. Intensive Care Med. 2006;32:1747-55.

21. Walkey AJ, Wiener RS. Use of noninvasive ventilation in patients with acute respiratory failure, 2000-2009: a population-based study. Ann Am Thorac Soc. 2013;10:10-7.

22. Nicolini A, Ferraioli G, Ferrari-Bravo M, Barlascini C, Santo M, Ferrera L. Early non-invasive ventilation treatment for respiratory failure due to severe community-acquired pneumonia. Clin Respir J. 2014.

23. Nava S, Schreiber A, Domenighetti G. Noninvasive ventilation for patients with acute lung injury or acute respiratory distress syndrome. Respir Care. 2011:56:1583-8.

24. Thille AW, Contou D, Fragnoli C, Cordoba-Izquierdo A, Boissier F, BrunBuisson C. Non-invasive ventilation for acute hypoxemic respiratory failure: intubation rate and risk factors. Crit Care. 2013;17:R269.
25. Antonelli M, Conti G, Esquinas A, Montini L, Maggiore SM, Bello G, et al. A multiple-center survey on the use in clinical practice of noninvasive ventilation as a first-line intervention for acute respiratory distress syndrome. Crit Care Med. 2007;35:18-25.

26. Azevedo LC, Park M, Salluh J, Rea-Neto A, Souza-Dantas VC, Varaschin P, et al. Clinical outcomes of patients requiring ventilatory support in Brazilian intensive care units: a multicenter, prospective, cohort study. Crit Care. 2013;17:R63.

27. Antonelli M, Conti G, Bufi M, Costa MG, Lappa A, Rocco M, et al. Noninvasive ventilation for treatment of acute respiratory failure in patients undergoing solid organ transplantation: a randomized trial. JAMA. 2000;283:235-41.

28. Razlaf P, Pabst D, Mohr M, Kessler T, Wiewrodt R, Stelljes M, et al. Noninvasive ventilation in immunosuppressed patients with pneumonia and extrapulmonary sepsis. Respir Med. 2012;106:1509-16.

29. Ferrer $M$, Torres $A$. Noninvasive ventilation for acute respiratory failure. Curr Opin Crit Care. 2015;21:1-6.

30. Schnell D, Timsit JF, Darmon M, Vesin A, Goldgran-Toledano D, Dumenil AS, et al. Noninvasive mechanical ventilation in acute respiratory failure: trends in use and outcomes. Intensive Care Med. 2014;40:582-91.

31. Esteban A, Anzueto A, Frutos F, Alia I, Brochard L, Stewart TE, et al. Characteristics and outcomes in adult patients receiving mechanical ventilation: a 28-day international study. JAMA. 2002;287:345-55.

32. Esteban A, Ferguson ND, Meade MO, Frutos-Vivar F, Apezteguia C, Brochard $L$, et al. Evolution of mechanical ventilation in response to clinical research. Am J Respir Crit Care Med. 2008;177:170-7.

33. Esteban A, Frutos-Vivar F, Muriel A, Ferguson ND, Penuelas O, Abraira V, et al. Evolution of mortality over time in patients receiving mechanical ventilation. Am J Respir Crit Care Med. 2013;188:220-30.

34. Barbas CS, Couto LP, Kawano-Dourado LB. Noninvasive ventilation for acute respiratory failure in patients with hematologic malignancies: what an Italian 5-year multicenter survey tells us. Crit Care Med. 2011;39:2358-9.

\section{Submit your next manuscript to BioMed Central and take full advantage of:}

- Convenient online submission

- Thorough peer review

- No space constraints or color figure charges

- Immediate publication on acceptance

- Inclusion in PubMed, CAS, Scopus and Google Scholar

- Research which is freely available for redistribution 